\title{
The Predictive Validity of The IELTS Test at Thai Nguyen University - Vietnam
}

\author{
Hoang Huong Ly, Ph.D \\ Thai Nguyen University of Technology \\ DOI: 10.29322/IJSRP.10.06.2020.p10292 \\ http://dx.doi.org/10.29322/IJSRP.10.06.2020.p10292
}

\begin{abstract}
In language testing and assessment, predictive validity of a test is probably considered as one of the most commonly discussed types of test validity because it is primarily dealt with the question of how accurate a test is as a predictor of academic performance. Therefore, this study examines the predictive validity of the International English Language Testing System (IELTS) as it determines the academic success of students, measured by cumulative grade point average (CGPA). The results indicate that IELTS scores seem not to be satisfactory predictors of academic achievement. It showed that IELTS Reading test score is a better fit for students' academic success. The study also addresses some recommendations of further language test use.
\end{abstract}

Index Terms- language testing and assessment, predictive validity, language proficiency, academic performance

\section{INTRODUCTION}

$I^{2}$ $\mathrm{n}$ recent times, there has been an increase in the number of overseas students choosing to study in universities in Englishspeaking countries. As a result, the issue of eligibility criteria has become an important one with measurement of proficiency in the English language being a key aspect. One of the most widely used tests for this purpose is the IELTS test developed by an international partnership between the University of Cambridge Local Examinations Syndicate (UCLES), the British Council, and IDP Education Australia.

The IELTS scores are required to get the admission into many universities around the world and many immigration destinations require the learners to take the IETLS in order to qualify the English requirements (Dooey \& Oliver, 2002; Huong, 2000; Rethinasamy, 2006). Huong (2000) emphasizes that the IELTS test serves as a useful medium to assess the language benchmark, and in other cases, to help learners find good opportunities for their future career.

Similarly, in our globalized world today, there is a growing use of test scores in accessing to higher education, and that English language proficiency has also become a dominant criterion for success in the labor market. Graham (1987: 515) argues that "English proficiency is only one among many factors that affect academic success".

Bearing this in mind, proficiency in the English language has been considered as a criterion to access most higher education program in every university, and the English language assessment plays a critical role in admission to higher education. However, there has always been raising a question about how predictive student scores in English language assessment are of student success in the future academic study.

In the light of the above discussion, the purpose of this study is to examine the relationship between the students' IELTS scores as an entrance score and their academic performance measured by their CGPA in order to establish IELTS as a predictor of academic performance.

\section{RESEARCH QUESTIONS}

The inconsistency of the results described above leaves the questions of the predictive validity. Therefore, the study aims to answer the research questions:

1. To what extent does the IELTS score predict the students' academic performance, measured by their CGPA?

2. Does any individual IELTS components (Listening, Writing, Reading and Speaking) predict students' academic success?

\section{Methodology}

\section{Participants}

Participants of this study comprised of 150 undergraduate students $(\mathrm{N}=150)$ who were studying English at Thai Nguyen University (TNU). More specifically, 61.2\% (91) of students were female and 38.8\% (59) of their academic year of 2016 - 2020. Before entering the university, these participants had taken the IELTS as the admission requirements. Table 1 shows the descriptive statistics of the participants.

Table 1: Descriptive statistics of the participants

\begin{tabular}{llllll}
\hline Participants & Academic year & \multicolumn{2}{l}{ Gender } & & \\
\cline { 3 - 6 } & & Female & $\%$ & Male & $\%$ \\
\hline 150 & $2016-2020$ & 91 & $61.2 \%$ & 59 & $38.8 \%$ \\
\hline
\end{tabular}




\section{DATA COLlECTION}

In attempting to establish IELTS as a predictor of academic performance, 150 students' IELTS entrance scores, first term average (GPA1), second term average (GPA2) and cumulative grade point average (CGPA) in the school year 20162020 were collected from university database.
Regarding the grading systems, Vietnamese educational system has implemented a common grading with both 10 point scale and 4 point scale. Firstly, students' typical grades are given in a course under 10 point scale, then converted into letter grade (from highest to lowest: A, B, C, D, and F) and 4 point scale. The grade $\mathrm{A}$ is excellent, $\mathrm{D}$ is below average, and anything less than a $\mathrm{D}$ is by definition failure. Table 2 presents the grading system used for students.

Table 2: Coding of numerical marks and letter grades

\begin{tabular}{llll}
\hline Average 10 point scale & Grade & Meaning & Band \\
\hline $8.5-10$ & A & Excellent & 4.0 \\
\hline $7.0-8.4$ & B & Good & 3.0 \\
\hline $5.5-6.9$ & C & Average & 2.0 \\
\hline $40-5.4$ & D & Below Average & 1.0 \\
\hline $0-3.9$ & F & Failing & 0 \\
\hline
\end{tabular}

Students' cumulative grade point average is then calculated based on the average of the grade points per the credits that students have just taken from their semesters.

Total points for semesters

of each student

= CPGA for the whole academic year

Total credits for semesters

\section{DATA ANALYSIS}

Data analysis was carried out in two stages. The first stage is to provide the results of the students' scores on IELTS as a whole and the scores on CGPA and this is accompanied by the results of the scores on each component of the IELTS. The results in the forms of descriptive and also bivariate statistics would be able to provide an overall picture of the performance of the students in all the measures used in the study.

For the second stage of the analysis, a stepwise multiple regressions were carried out in order to determine which of the IELTS components proved to be the best predictor of academic achievement as measured by CGPA. Predictor variables such as students' overall IELTS scores, scores on components of IELTS were analyzed against students' GPA1, GPA2, CGPA which were used as dependent variables.

\section{RESULTS}

Figure 1 shows the distribution of students' grades according to their IELTS band.

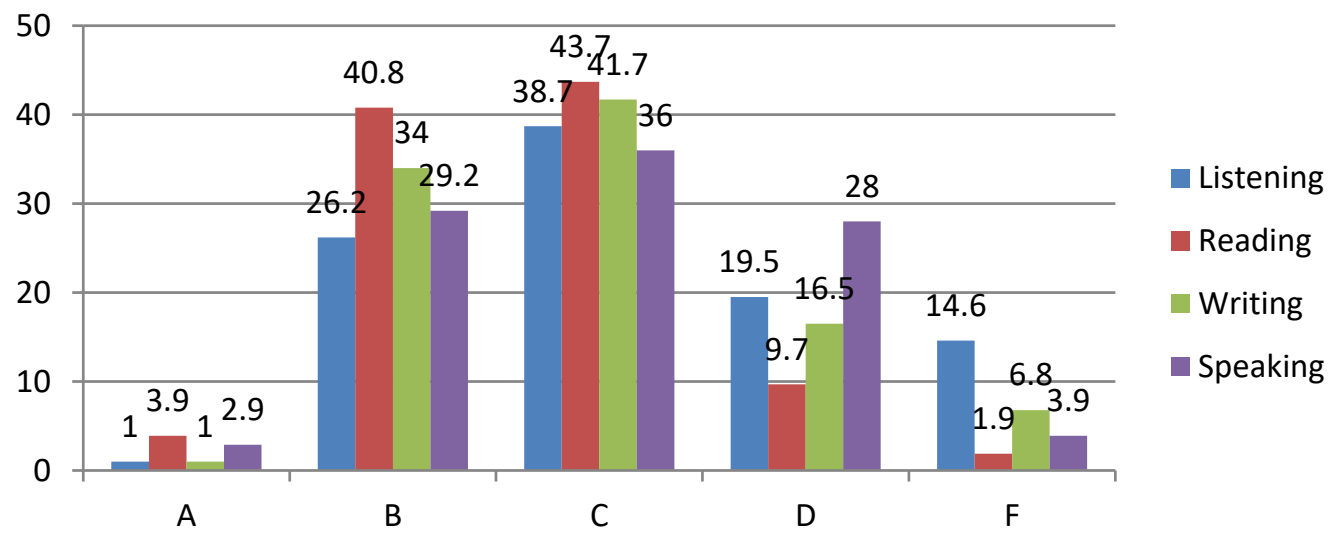

Figure 1. Distribution of students' IELTS scores $(N=150)$

In general, Figure 1 shows that four IELTS components were mainly distributed towards the grades C, B and D. On the other hand, IELTS students' results were slightly distributed towards the left with the grade A and the right with the grade F. A closer observation of these grade categories show that most of the students (43.7\% and $40.8 \%$ respectively) obtained the average (grade C) and good (grade B) in the reading component as compared to other components. In contrast, only minority the students, ranging from $1 \%$ to $3.9 \%$, were able to achieve the grade excellent A. The results also show that a small percentage of the 
students, ranging from $1.9 \%$ to $14.6 \%$, failed the course, especially the failures in the listening component were the highest with $14.6 \%$

In order to enrich the status of students' performance on IELTS, the descriptive statistics results for the IELTS were calculated. Table 3 shows the means and the standard deviations of the IELTS overall score and CGPA scores of 150 students in the school year 2016-2020.

Table 3: Descriptive statistics results for the IELTS scores $(N=150)$

\begin{tabular}{llllll}
\hline & Min & Max & Mean & SD & Number \\
\hline IELTS overall & 3.0 & 6.5 & 6.084 & .8508 & 150 \\
\hline IELTS Listening & 2.0 & 5.5 & 5.791 & 1.550 & 150 \\
\hline IELTS Reading & 3.0 & 6.5 & 5.505 & 1.147 & 150 \\
\hline IELTS Writing & 3.0 & 6.0 & 6.087 & 1.291 & 150 \\
\hline IELTS Speaking & 3.0 & 6.5 & 5.961 & 1.364 & 150 \\
\hline
\end{tabular}

As can be shown from Table 3, the minimum IELTS overall score obtained by 150 students was Band 4.0 while the maximum was Band 6.5. On average, the students scored 6.084 in the IELTS, showing that the sample as a whole seems to satisfy the level of English required for academic study at undergraduate at universities.

As for the students' four IELTS component scores, it can be noted that, the minimum for Reading, Writing and Speaking components got the same Band 3.0 while the lowest Band 2.0 was for Listening Component. The maximum for both Speaking and Reading components are the highest with Band 6.5, followed closely for Listening and Writing components at Band 8.5. On the averaged mean score, the highest mean score $(\mathrm{M}=6.087, \mathrm{SD}=$ 1.291) was for Writing Component while the lowest was accounted for Reading Component with the mean score of 5.505. The means for the rest of the components were all above 5.5. Table 4 shows the descriptive statistics students' academic performance.

Table 4: Descriptive statistics for GPA1, GPA2 and CGPA $(N=150)$

\begin{tabular}{lllll}
\hline & Min & Max & Mean & SD \\
\hline GP1 & 6.1 & 8.2 & 6.893 & .9357 \\
\hline GP2 & 5.7 & 8.7 & 7.005 & .4306 \\
\hline CGPA & 6.1 & 8.5 & 6.958 & .5735 \\
\hline
\end{tabular}

As can be seen from Table 4, for first semester, the minimum score was Band 6.1 while the maximum was Band 8.2. On average, the students achieved GPA1 of 6.893. Similarly, the minimum in the second semester was Band 5.7 meanwhile the maximum was Band 8.7. On average, the students scored GPA2 of 7.005 .

Last but not least, the minimum for the academic performance of the first whole year was Band 6.1 while the maximum was Band 8.5. On the averaged mean score, the students obtained CGPA of 6.958. As mentioned earlier, the highest grade assigned for grading system used at the university is 10.0 (see Table 4), therefore the sample with the averaged mean of 6.958 reveals that students as a whole perform standardly well their academic achievement.
In attempt to establish the IELTS as predictor of academic performance, correlation between test scores was calculated. According to Garrett and Woodworth (1958:122), "correlation method is used to examine the relationship of one variable to another" and that 'correlation is simply a measure of mutual association between two variables' (p. 180).

As all these references indicated above, Pear Correlation was run to investigate the relationship between the IELTS overall score and its component scores and CGPA obtained by 150 students.

First of all, the correlation coefficient between the IELTS component scores and CGPA was computed to give a rich descriptive picture of the relationship between the variables.

Table 5: Correlations between the IELTS components and CGPA $(N=150)$

\begin{tabular}{lll}
\hline CGPA & & \\
\hline IELTS Listening & $\begin{array}{l}.150 \\
(\mathrm{p}=0.129)\end{array}$ & \\
& & $\begin{array}{l}.354^{* *} \\
(\mathrm{p}=0.01)\end{array}$ \\
\hline IELTS Reading & & \\
& & $\begin{array}{c}.187 \\
(\mathrm{p}=0.058)\end{array}$ \\
\hline IELTS Writing & & .133 \\
\hline IELTS Speaking & & \\
\hline
\end{tabular}




\begin{tabular}{ll}
\hline & $(\mathrm{p}=0.179)$ \\
\hline IELTS Overall & $.323^{* *}$ \\
& $(\mathrm{p}=.002)$ \\
\hline
\end{tabular}

** Correlation is significant at the 0.01 level (2 tailed)

* Correlation is significant at the 0.05 level (2 tailed)

The noteworthy point from Table 5 is that insignificant correlations between Listening $(\mathrm{r}=0.150, \mathrm{p}=0.129)$, Writing $(\mathrm{r}=$ $0.187, \mathrm{p}=0.058)$, Speaking $(\mathrm{r}=0.133, \mathrm{p}=0.179)$ and CGPA. However, the correlations between IELTS Reading and CGPA; IELTS overall score and CGPA have a slightly better predictive value than the others. More specific, the highest correlation is the correlation between Reading and CGPA with the $r$ value of 0.354 , then followed closely by the correlation between IELTS overall and CGPA ( $r=0.323, \mathrm{p}=.002)$.

Table 6 shows correlations between the IELTS Components, overall band score and GPA1, GPA2.

Table 6: Correlations between IELTS scores and GPA1, GPA2 (N=150)

\begin{tabular}{lll}
\hline & GPA1 & GPA2 \\
\hline IELTS Listening & .042 & .243 \\
& $(p=.671)$ & $(p=.013)$ \\
\hline IELTS Reading & $.305^{* *}$ & $.379^{*}$ \\
& $(p=.002)$ & $(p=.001)$ \\
& .127 & .105 \\
IELTS Writing & $(p=.203)$ & $(p=.038)$ \\
& .037 & .175 \\
IELTS Speaking & $(p=.713)$ & $(p=.077$ \\
& $.237^{*}$ & $.287^{* *}$ \\
IELTS Overall & $(p=.016)$ & $(p=.003)$ \\
&
\end{tabular}

** Correlation is significant at the 0.01 level (2 tailed)

* Correlation is significant at the 0.05 level (2 tailed)

Table 6 generally shows that correlations between each IELTS component scores and GPA1, GPA2 range from the lowest of 0.105 to the highest of 0.379). In specific, high scores on the Reading and overall band scores tend to associate with high scores on GPA1 and GPA2, but the association seems to decrease with GPA1 as compared to GPA2. The similar thing also occurs to the Writing and Speaking however, none of the statistically significant correlations was found between Writing and GPA1, GPA2 as well as between Speaking and GPA1, GPA2.

These results are satisfying in light of what Alderson, Clapham and Wall noticed "... in predictive validity studies, it is common for test developers and researchers to be satisfied when they have achieved a coefficient as low as 0.3" (Alderson, Clapham \& Wall, 1995: 182). Furthermore, previous predictive validation studies (Criper \& Davies, 1988; Graham, 1987) suggest that 0.30 is as high a correlation as can be expected when doing the research on the predictive validity. Furthermore, a typical standardized regression coefficient of around 0.3 was common among many of these studies (Elder, 1993; Ferguson and White, 1993; Cotton and Conrow, 1998; Hill et. al, 1999; Kerstjens and Nery, 2000).

As all these references indicated above, it can be assumed that there is some evidence supporting for the predictive validity of the IELTS in which the correlation between IELTS overall band score and CGPA; the correlations between Reading component and GPA1, GPA2, CGPA (see Table 5 and 6). Therefore, Reading Component of the IELTS is only the best significant predictor of students' academic success.

As mentioned, the correlations between IELTS overall, subtest scores with GPA1, GPA2 and CGPA imply that there is a small correspondence between performance on the test and students' academic performance for this study. To confirm this correspondence, in the second stage of the analysis, a stepwise regression was carried out. Regression analysis refers to "a broad class of statistical techniques that are designed to study the relationship between a criterion (or dependent variable), $Y$, and one or more predictors (or independent variables), $X 1, X 2, \ldots, X$ " (Tatsuoka, 1997: 648). Indeed, many researchers used regression analysis to conduct the relationship of their English language proficiency tests with academic performance measured by CGPA (Feast, 2001, Karakaya \& Tavsancil, 2008; Kucuk, 2001; Sar, 2008).

In the light of the references above, in this confirmatory stage, the key independent variables were IELTS components and overall band score while students' academic performance measured by CGPA was used as a dependent variable. The purposes of this stage are to confirm the findings in the first stage as well as to prove the best predictor of academic achievement as measured by CGPA. Table 7 shows R square, and $\beta$ weight of the IELTS components and overall score with CGPA. 
Table 7: Regression analysis results of IELTS components and overall score $(N=150)$

\begin{tabular}{llllll} 
& Predictor & $\boldsymbol{\beta}$ & R2 & t-value & Sig. \\
\cline { 2 - 6 } & IELTS Listening & .042 & .023 & 1.529 & .129 \\
\cline { 2 - 6 } IELTS Reading & .129 & .112 & 3.566 & .001 \\
\hline IELTS Writing & .062 & .035 & 1.916 & .058 \\
\cline { 2 - 5 } IELTS Speaking & .042 & .018 & 1.352 & .179 \\
\cline { 2 - 5 } & IELTS overall score & .153 & .092 & 3.195 & .002 \\
\hline
\end{tabular}

** Correlation is significant at the 0.01 level (2 tailed)

* Correlation is significant at the 0.05 level (2 tailed)

As shown in Table 7, the results of a stepwise multiple regression were not high, R- square ranges from .018 to .112. Among the variables, only Reading component in the IELTS proved to be significant predictor of success in CGPA in which the accounted variance was $11.2 \%, \mathrm{t}=3.566, \mathrm{p}=0.01$, then followed by the overall score in which variance was $9.2 \%, \mathrm{t}=3.195, \mathrm{p}=.002$. It means that, there were $11.2 \%$ and $9.2 \%$ of the agreements between Reading component, overall score and their CGPA respectively. In other words, IELTS Reading component and the IELTS overall band score accounted for $11.2 \%$ and $9.2 \%$ of the variance of success in CGPA, corresponding to a small- to - medium predictive effect of academic performance (Cohen, 1992). In contrast, other components could not be predictors in predicting CGPA achievement by confirming the low correlation of 0.023 for Listening 0.035 for Writing 0.018 for Speaking component and 0.092 for overall band score.

From the data shown in Table 7, although the IELTS Reading component showed higher predictive evidence than the other three components: Listening, Writing and Speaking, the results were generally weak. Thus, it can be clearly said that the IELTS could not predict CGPA results, or in other words, the IELTS cannot predict the students' academic success.

\section{FINDINGS AND DISCUSSION}

As all these references indicated above, it can be concluded that there are some existing relationship between the IELTS test scores and CGPA, however these correlations are weak. In specific, the correlation between the IELTS test's overall score and CGPA had a better predictive value than GPA1, GPA2. The IELTS Reading component showed a bit higher predictive evidence than the other three components: Listening, Writing and Speaking. This finding suggests that the IELTS, on the whole, does not predict the students 'academic achievement in a public university in Vietnam.

This is in line with the conclusions drawn from similar previous studies conducted on the predictive validity of various local English language tests (Davies, 1990; Elder, 1993; Cope, 2011; Hajr, 2014; Lynch, 2000). Though these studies varied in the sample sizes, levels of education, and measures of the standardized language tests and academic achievement, most of them concluded that the correlation between the standardized language tests and academic achievement was weak to moderate, between 0.2 and 0.4. More particularly, Dooey (1999) proved the evident that it has been difficult to find strong predictive relationship between IELTS and students' academic achievement. Similarly, Bẹnlingham (1999) explained for his finding was if these results were conducted with IELTS Band 4.0 and above, the students may have $20 \%$ chance of success in their academic performance. This implies that, students who got overall IELTS entrance score of 4.0 and above may perform little bit better their academic susccess. In contrast, it seems to be hard to achieve academic achievement for those who got IELTS entrance below 4.0. Constantly, Benlingham (1999) went on say that only IELTS Band 6.5 and above - the requirement for all university admission "is less likely to be a significant factor in influencing academic success" (p.231).

\section{CONCLUSION}

From the correlation results above the IELTS and CGPA have slightly significant relationship. Only Reading component in the IELTS emerged as a satisfactory predictor of the students' academic performance as measured by their CGPA. Based on the findings of the study it is suggested that other components: Writing, Listening and Speaking should be paid more attention in the selection of students who apply for a position in the university. More importantly, in order to build a more comprehensive picture of the relationship between students' English proficiency and their academic success, the educators should take more considerations of other factors which affect on academic performance as well as key influences on the admission criteria.

\section{ACKNOWLEDGEMENTS}

This paper is supported by Thai Nguyen University of Technology - Vietnam.

\section{REFERENCES}

[1] Advi, E. (2003). IELTS as a predictor of academic achievement in a Master's Program. English Australia Journal, 26(2), 42-49.

[2] Ajibade, A.Y. (1993). Proficiency in English and affective factors as predictors of senior secondary school students' achievement in French (Unpublished doctoral thesis). University of Ibadan, Nigeria.

[3] Bachman, L. F. (1990). Fundamental Considerations in Language Testing, Oxford, UK: Oxford University Press. 
[4] Bachman, L. F. (1981). Languages for specific purposes: Program design and evaluation. Formative evaluation in ESP program development. Rowley, Massachusetts: Newbury House.

[5] Bernstein, J., Van Moere, A., \& Cheng, J. (2010). Validating automated speaking tests. Language Testing, 27(3), 355-377.

[6] Chao, J. Y-G. (2013). Factors affecting college English Foreign Language learners' listening comprehension and listening problems. NCUE Journal of Humanities, 8, 71-84.

[7] Cohen, J. (1988). Statistical power analysis for the behavioral sciences (2nd edition). Hillsdale, New Jersey: Lawrence Erlbaum Associates.

[8] Coley, M. (1999). The English language entry requirements of Australian universities for students of non-English speaking background. Higher Education Research and Development, 18 (1), 7-17.

[9] Crocker, L., \& Algina, J. (1986). Introduction to Classical and Modern Test Theory. Philadelphia, U.S: Harcourt Brace Jovanovich College Publishers.

[10] Crystal, D. (2000). English as global language. Cambridge, UK: Cambridge University Press.

[11] Dooey, P., \& Oliver, T. R. (2002). An investigation into the predictive validity of the IELTS as an indicator of future academic success. Prospect, $17(1), 36-54$

[12] Henning, G. (1984). Current Developments in Language Testing. Language Testing in Asia, 1, 237-241.

[13] Huong, T.T.T. (2000). Investigating the predictive validity of IELTS among Vietnamese students (Unpublished doctoral thesis). La Trobe University, Australia.
[14] Ghenghesh, P. (2015). The relationship between English language proficiency and academic performance of university students. International Journal of Applied Linguistics and English Literature, 4 (2), 91 - 97.

[15] Rethinasamy, S., \& Chuah, K. M. (2011). The Malaysian University English Test ( MUET ) and its use for placement purposes: A Predictive validity study. Electronic Journal of Foreign Language Teaching, 8 (2), 234-24.

[16] Riazi, M. (2013). Concurrent and predictive validity of Pearson Test of English Academic. Language Testing and Assessment, 2(2), 1-27.

\section{AUTHORS}

First Author - Dr. Hoang Huong Ly is currently a lecturer of English at Thai Nguyen University of Technology. She earned her bachelor degree in English Language Teaching at Thai Nguyen University and the degree of Master of Applied Linguistics majoring in TESOL at La Trobe University, Australia. She holds the degree of $\mathrm{Ph}, \mathrm{D}$ in English Language and Literature at Batangas State University, The Philippines. Her interests include English Phonetics and Phonology, Writing Skills and Teaching Methodology. 